\title{
Efficacy and Side Effects of Deferasirox and Deferiprone for Thalasemia Major in Children
}

\author{
Asti Y. Rindarwati ${ }^{1}$, Ajeng Diantini ${ }^{2}$, Keri Lestari ${ }^{2}$ \\ ${ }^{1} \mathrm{~K}-24$ Pharmacy, Bandung, West Java, Indonesia \\ ${ }^{2}$ Department of Pharmacology and Clinical Pharmacy, Faculty of Pharmacy, \\ Universitas Padjadjaran, Jatinangor, West Java, Indonesia
}

\begin{abstract}
Thalassemia major (TM) is an inherited disease caused by defective or absent of hemoglobin chain synthesis. Regular chelation therapy is necessary to reduce excess iron in several organs of TM patients. The most commonly used chelating agents are deferasirox and deferiprone. However, information regarding their effectiveness and side effects in Indonesian children population with TM were limited. This study was conducted to assess the effectiveness and side effects of deferasirox and deferiprone in pediatric patients with TM. This was an observational study with prospective analysis which was conducted during April-August 2015. We included pediatric patients with TM who visited a hospital in Bandung, Indonesia, using consecutive sampling method. Thirty two subjects were divided into two groups, i.e., deferasirox and deferiprone group. Review of medical records and interview were performed for each participants. Effectiveness was defined as reduction in ferritin level. Side effects were assessed using Naranjo scale. Data were analyzed using Mann-Whitney test, Wiloxon test and Chi square test. P value $<0.05$ defined statistical significance. We found that deferasirox was more effective than deferiprone for the treatment of TM in pediatric patiens, with less side effects. The use of deferasirox as iron chelating agent is recommended for patients with TM.
\end{abstract}

Keywords: deferasirox, deferiprone, ferritin, thalassemia major

\section{Introduction}

Thalassemia major (TM) is an inherited disease caused by defective or absent of hemoglobin chain synthesis. TM genes are particularly frequent among the people of Mediterranean origin, Middle East, and South East Asia, including Indonesia. The World Health Organization (WHO) reported that about $7 \%$ of the world's population is TM carriers and approximately 300,000 to 500,000 babies are born with TM every year. ${ }^{1}$ TM patients should undergo monthly transfusions during their lifetime in order to maintain hemoglobin level in the range of 9-10 g/dl. However, transfusion can not

Corresponding author: Asti Y. RIndarwati. K-24 Pharmacy, Bandung, West Java, Indonesia.

Email: asti.rindarwati@gmail.com

Received: 9 September 2016. Revised: 12 November 2016. Published: 1 December 2016. 
prevent accumulation of $200 \mathrm{mg}$ of iron in various organs. Therefore, the use of chelating agent is necessary to reduce excess iron in some organs. ${ }^{2}$

Chelation therapy can be started if TM patients had undergo transfusion as much as 10-20 times or ferritin value has reached $1000 \mathrm{mg} / \mathrm{dl}$ The side effects generated by each chelating agent can be anticipated by monitoring the function of liver and kidney function periodically. The most commonly chelation therapy used by thalassemia patients is deferasirox and deferiprone. ${ }^{3}$

Deferasirox used for treating iron toxicity by making a bond with trivalent iron and forming a stable complex that is eliminated via the kidneys. Deferiprone is also chelating agent which is more selective to iron. ${ }^{4}$ Chelation therapy requires compliance and thorough attention to the proper way of administration. Desired therapeutic effect can be reached with such actions. ${ }^{5}$ Information regarding deferasirox and deferiprone effectiveness and side effects in Indonesian children population with TM was limited.
This study was aimed to assess the efficacy and safety of deferasirox and deferiprone in Indonesian patients with TM.

\section{Methods}

The population of this study was TM pediatric patients attending the outpatient clinic at Dr. Hasan Sadikin General Hospital, Bandung, during 2015. We included pediatric patients who received blood transfusions $>10$ times or had serum ferritin level $>1,000 \mathrm{ng} / \mathrm{m}$, received deferiprone or deferasirox therapy, aged between 6-12 years, and had complete medical records, i.e., the monthly results of serum creatinine and ureum, quarterly results of ferritin, SGOT, and SGPT. We excluded patients who used the combination of deferasirox and deferiprone therapy. ${ }^{6}$

This was an observational studies with prospective cross-sectional analysis. The study was conducted by reviewing medical records and interviewing the patients during April until August 2015. From each medical records, we extracted data regarding name, sex, age, volume of tranfusion, ferritin serum,

Table 1. Characteristics of participants

\begin{tabular}{|c|c|c|c|}
\hline \multirow[b]{2}{*}{ Characteristics } & \multicolumn{2}{|c|}{ Chelating agents } & \multirow[b]{2}{*}{ P-Value } \\
\hline & $\begin{array}{c}\text { Deferasirox } \\
(n=16)\end{array}$ & $\begin{array}{c}\text { Deferiprone } \\
(\mathrm{n}=16)\end{array}$ & \\
\hline \multicolumn{4}{|l|}{$\operatorname{Sex}$} \\
\hline Male & 11 & 8 & $0.280 *$ \\
\hline Female & 5 & 8 & \\
\hline \multicolumn{4}{|l|}{ Age (years) } \\
\hline Mean (SD) & $8.4(2.9)$ & $7.8(3.8)$ & $0.838 * *$ \\
\hline Median & 8.5 & 9.5 & \\
\hline Range & $3-13$ & $3-12$ & \\
\hline \multicolumn{4}{|l|}{ Transfusion Volume $(\mathrm{ml})$} \\
\hline Mean (SD) & $299.1(93.5)$ & $261.2(110.6)$ & $0.445^{* *}$ \\
\hline Median & 337.7 & 337.7 & \\
\hline Range & $90-390$ & $110-375$ & \\
\hline
\end{tabular}


Table 2. Level of ferritin at pre- and post- chelating treatment

\begin{tabular}{|c|c|c|c|}
\hline \multirow[b]{2}{*}{ Feritin Level (mg/dl) } & \multicolumn{2}{|c|}{ Chelating agents } & \multirow[b]{2}{*}{ P-Value } \\
\hline & $\begin{array}{l}\text { Deferasirox } \\
\quad(n=16)\end{array}$ & $\begin{array}{c}\text { Deferiprone } \\
(\mathrm{n}=16)\end{array}$ & \\
\hline $\begin{array}{c}\text { Pre-treatment: } \\
\text { Mean (SD) } \\
\text { Median } \\
\text { Range }\end{array}$ & $\begin{array}{c}4415.7(1831.3) \\
3804.5 \\
2332-7989\end{array}$ & $\begin{array}{c}2996.8(1885.4) \\
2316 \\
1020-6562\end{array}$ & $0.029^{*}$ \\
\hline $\begin{array}{c}\text { Post-treatment: } \\
\text { mean (SD) } \\
\text { Median } \\
\text { Range }\end{array}$ & $\begin{array}{c}2552.1(1446.9) \\
2096 \\
1101-5960\end{array}$ & $\begin{array}{c}3278.1(2091.2) \\
2420 \\
1010-7689\end{array}$ & $0.402 *$ \\
\hline $\begin{array}{l}\text { Comparison between pre- vs } \\
\text { post-treatment ( } \mathrm{p}^{* *} \text { Value) }\end{array}$ & $<0.001$ & 0.326 & \\
\hline $\begin{array}{c}\text { Percentage of ferritin reduction } \\
\text { Mean (SD) } \\
\text { Median (Range) }\end{array}$ & $\begin{array}{c}43.3(17.9) \\
41.5(6.4-70.3)\end{array}$ & $\begin{array}{c}-16.6(52.1) \\
-2.0(-189.1-34.4)\end{array}$ & $<0.001$ \\
\hline
\end{tabular}

*) Mann-Whitney test **) Wilcoxon test

creatinine, urea, SGOT, and SPGT. Interview was conducted using Naranjo scale to assess side effects based on patients reported outcomes. ${ }^{5}$ Data were analyzed using student t-test, chi-square, Mann-Whitney, and Wilxocon tests. $\mathrm{P}<0.05$ defined statistical significance.

\section{Results and Discussion}

Thiry two participants were included in this study. Participants were then divided into two groups based on the type of chelation therapy used, including deferasirox or deferiprone. General characteristics of the subjects can be found in Table 1. Based on the chi-square analysis, there was no association between gender, age, and transfusion volume on the type of chelating agents used.

Initial dose of deferiprone was $75 \mathrm{mg} / \mathrm{kg}$ of BW per day, while that of deferasirox was 20 $\mathrm{mg} / \mathrm{kg}$ of BW per day. Previous study showed that the use of this dose is effective in the binding and excreting excess iron. ${ }^{2}$

Reduction of ferritin in deferasirox group was significantly different with that of deferiprone (Table 2). The mean value of ferritin reduction in deferasirox was 45.76

Table 3. Reduction of ferritin by including urea and creatinine level variable

\begin{tabular}{lcc}
\hline \multicolumn{1}{c}{ Variation resources } & F count & P-value \\
\hline Ureum & 0.006 & 0.941 \\
Creatinine & 0.240 & 0.628 \\
Chelating agents & 13.655 & 0.001 \\
\hline
\end{tabular}

Mean of $\%$ reduction

Feritin level (CI 95\%):

Deferasirox

Deferiprone

$-19.05(-42.2-4.06)$ 
Table. 4 SGOT, SGPT, ureum, and creatinine level among participants

\begin{tabular}{lccc}
\hline Variable & \multicolumn{2}{c}{ Chelating agents } & P-Value \\
\cline { 2 - 3 } & $\begin{array}{c}\text { Deferasirox } \\
(\mathbf{n = 1 6 )}\end{array}$ & $\begin{array}{c}\text { Deferiprone } \\
(\mathbf{n}=\mathbf{1 6})\end{array}$ & \\
\hline SGOT & $36.2(9.2)$ & $38.9(21.4)$ & 0.648 \\
Mean (SD) & 35 & 42 & \\
Median & $22-52$ & $8-76$ & \\
Range & & & 0.491 \\
SGPT & $33.3(8.7)$ & $39.2(19.1)$ & \\
Mean (SD) & 31.5 & 33.5 & \\
Median & $20-47$ & $25-95$ & 0.048 \\
Range & & & \\
& $18.2(2.2)$ & $22.6(8.3)$ & \\
Ureum & 18 & 21 & \\
Mean (SD) & $15-22$ & $12-36$ & \\
Median & & & \\
Range & $0.27(0.05)$ & $0.33(0.05)$ & \\
Creatinine & 0.27 & 0.32 & \\
Mean (SD) & $0.21-0.35$ & $0.25-0.42$ & \\
Median & & & \\
Range & &
\end{tabular}

(22.66-68.87), while that of deferiprone was 19.05 (4.06-42.2). This finding was comparable with previous study. However, patients treated with deferiprone had less myocardial iron burden due to its ability to remove cardiac iron. The combination of these two drugs could potentially result in more favourable results ${ }^{6-10}$

Patient adherence is one the major issues in the treatment with chelating agents in TM patients. One of the driving factors of the adherence is the inconvenient dosing schedule. The use of once daily dosage of deferasirox is more likely to be resulted in the improvement in patients adherence to medication. ${ }^{11}$

In this study, the assessment of side effect was performed by conducting the interview with participants using the Naranjo scale. Within the Naranjo scale, there were 10 questions related to the adverse events experienced by the patiens during the therapy. We found that more patients in deferipirone groups reported side effects. The use of chelating agent was significantly associated with the increasing level of ureum and creatinine (Table 4). In TM patients, the incomplete formation of erythrocite could result in anaemia. This condition may alter the functions of the kidney. ${ }^{13}$

Previous study showed that long term use of chelating agent may induce hepatotoxicity. ${ }^{12}$ In this study, the parameters related to the liver functions, such as SGOT and SGPT, were not significantly different between the two groups (Table 4). It might be caused by the relatively similar time range in the use of chelating agents among the participants. Patients with pre-existing liver disease should use 
chelating agent with caution. Polymorphisms of the hepatic genes known to be involved in deferasirox excretion may also influence the development of hepatotoxicity. ${ }^{12}$

\section{Conclusion}

Deferasirox was more effective than deferiprone for the treatment of TM in pediatric patients, with less side effects. The use of deferasirox as iron chelating agent is recommended for patients with TM.

\section{References}

1. Cao A, Galanello R. $\beta$-thalassemia. Genetic Medicines. 2010;12:61-76.

2. Taher A, El-Beshlawy A, Mohsen S. Efficacy and safety of deferasirox an oral iron chelator in heavily iron overloaded patients with beta thalasemia. European Journal of Haematology. 2009;(82):458463.

3. Malik S, Chatterjee S, Mandal PK, et al. Expenditure to treat thalassemia: experience at a tertiary care hospital in India. Iranian Journal of Public Health. 2010; (39):78-84.

4. Galanello R, Origa R. Beta-thalassemia. Orphanet Journal of Rare Disease. 2010; 5(11):1-15.

5. Olivieri NF. Treatment strategies for hemoglobin e beta thalasemia. Blood Reviews. 2012;4(26):28-30.

6. Capellini MD, Cohen A, Piga A, et al. A phase 3 study of deferasirox, a once daily oral iron chelator, in patient with beta thalasemia. Blood. 2006;107(9):34553462.

7. Elalfy MS,AdlyAM, WaliY,etal. Efficacy and safety of a novel combination of two oral chelators deferasirox/deferiprone. European Journal of Hematology. 2015:95(5);411-420.

8. Totadri S, Bansal D, Bhatia P. The deferiprine and deferasiroc combination is efficacious in iron overloaded patients with thalasemia major. Pediatric Blood Cancer. 2015;62(9):1592-1596.

9. Gardenghi S, Marongiu MF, Ramos P, et al. Ineffective erythropoiesis in beta thalasemia. Blood. 2007;109(11):50275035.

10. Neufeld EJ. Oral chelators deferasirox and deferiprone for transfusional iron overload in thalassemia major. Blood. 2006;107(9):3436-3441.

11. Oikonomidou PR, Casu C, Rivella S. New strategies to target iron metabolism for the treatment of beta thalassemia. Annuals of the New York Academy of Sciences. 2016;1368(1):162-168.

12. Neupane GP, Kim DM. Comparison of the effects of deferasirox, deferiprone, and deferoxamine on the growth and virulence of Vibrio vulnificus. Transfusion. 2009;4:1762-1769.

13. Vichinsky E. Oral chelators and the treatment of iron overload in pediatric patients. Pediatrics. 2008:12;54. 